\title{
How to Identify Disadvantage: Taking the Envy Test Seriously
}

In this paper, I am concerned exclusively with the kind of comparative disadvantage an individual suffers in having less valuable opportunities than another individual, and that may entitle her to corrective action, such that we ought to regulate the risk of this disadvantage and/or consider compensating her if she suffers disadvantage. The dominant approach in both political philosophy and public policy to identifying this kind of disadvantage is to employ one or another kind of metric. By this, I mean that we identify an individual as disadvantaged by virtue of the fact that she enjoys less than others of some specified good or goods. On this view, we should treat an individual as disadvantaged if and only if her opportunities afford her an objectively lower level of wellbeing, a lower level of welfare, or fewer social primary goods, say. ${ }^{1}$ Let's call this the metric test.

However, there is another way in which to proceed. Rather than appeal to a metric to determine disadvantage, we could instead allow an individual to determine for herself whether or not she is disadvantaged. On the version of this view that I shall defend, we should treat an individual as disadvantaged if and only if that individual envies another's opportunities. Let's call this the envy test. ${ }^{2}$ A distinctive feature of the envy test is that it consults, rather than usurps, an individual's own evaluation of the comparative value of her opportunities. ${ }^{3}$ An individual can determine for herself whether or not she is disadvantaged, rather than have it determined for her by an external agent who reaches judgments that may not be fully consistent with what she believes (Dworkin, 2000: 294). This is initially appealing for two reasons. First, it takes seriously the idea that the political morality of a community should be justifiable to each of its members. ${ }^{4}$ Second, it guarantees the avoidance of disrespectful judgments, such as when a state treats an individual as disadvantaged even though she maintains that she is not (Dworkin, 2011: ch. 16).

I have three main aims. The first is to clarify the demands of the envy test. The second is to illuminate with greater clarity the appeal of the envy test and, in particular, to explain its superiority over the metric test. The third is to rebut an objection to the envy test: the mistakes objection. This objection holds that we should reject the envy test on the 
grounds that it implausibly allows the claim that an individual is disadvantaged to depend upon her mistaken judgments. My overall aim, therefore, is to offer a clear presentation and defence of the envy test.

At the outset, it is essential to stress that, whilst the envy test states necessary and sufficient conditions for an individual to qualify as disadvantaged, these conditions govern only a specific form of comparative disadvantage. It is consistent with the view that I defend here that an individual may be disadvantaged in other respects, even if she does not envy another's opportunities. That is, even if an individual is not disadvantaged according to the envy test, and so not entitled to corrective action on grounds of suffering a specific form of comparative disadvantage, she may none the less be entitled to corrective action for other reasons, such as out of a concern for democratic values or political equality. ${ }^{5}$ In other words, my approach is consistent with the idea that there are a diversity of reasons to oppose relative disadvantage. I briefly return to this point in section $\mathrm{V}$.

\section{The Envy Test}

The term 'envy' has various connotations. On one reading, which perhaps aligns with ordinary language, an individual is envious if, when she cannot (also) possess an opportunity that another enjoys, she prefers that the other individual not have it either (Nozick, 1974: 239). ${ }^{6}$ Understood in this way, envy is an emotion or judgment closely associated with jealousy and spite (Rawls, 1999: 466). As Elizabeth Anderson notes, this can make its use inadvisable, for it is likely both to fuel libertarian critiques of distributive justice and to foster a disrespectful culture of contemptuous pity directed at individuals regarded as sadly inferior (1999: 289 and 307).

Importantly, the envy test does not understand envy in this way. Rather, the envy test stipulatively states that an individual suffers disadvantage if and only if her opportunities are less valuable than those enjoyed by another individual, as measured by her own judgments about what makes one's life go well. Thus, it is an individual's own values that determine whether or not she is disadvantaged. We can express this component of the envy test in the following way: for an individual to envy another's opportunities, her sincerely held values must imply that her own opportunities are less valuable. This 
distinguishes envy as it is used by the envy test from the sense of envy criticised by Anderson (Dworkin, 2000: 117 fn. 19). To clarify this, let's consider the following case:

Talent: Due to the high marketability of her natural talents, Lucky enjoys a wide range of opportunities to which she attaches considerable value. By contrast, and due to the lack of marketability of her natural talents, Unlucky does not. Unlucky regards Lucky's opportunities as more valuable than her own.

Since Unlucky regards Lucky's opportunities as more valuable than her own, she counts as disadvantaged, according to the envy test. The fact that Unlucky is (or is not) disadvantaged according to some objective account of well-being, say, affects this result only in so far as it affects Unlucky's own judgments about the value of her opportunities. This feature of the envy test may strike some readers as counter-intuitive. It is therefore imperative to explain and to justify this result. I take up this task in subsequent sections.

Finally, it is important to note that the envy test is not necessarily sensitive to an individual's actual judgments. This is for two reasons. First, what matters is that her values must imply that her own opportunities are less valuable than another's, irrespective of whether or not she actually makes the judgment or forms that belief (Williams, 2002b: 387). I return to this point in section IV. The second reason for eschewing appeals to actual judgments relates to the fact that they may be held only as a result of injustice or irrationality. To see this point, let's consider an individual who fails to value an opportunity that she otherwise would only as a result of unjust indoctrination, such that, were it not for the unjust indoctrination, she would regard herself as disadvantaged (Sen, 1987: 11). It is clear that our judgment about whether she is disadvantaged should be unaffected by the unjust indoctrination that the individual experiences. We can deliver this result by restricting the envy test's concern to authentic judgments only. Though we must specify what counts as an authentic judgment so as to rule out the two kinds of case that I mention above, I shall say nothing more about this. For the most part, I put aside these two complications.

\section{The Appeal of the Envy Test}

The metric test proceeds in two stages. First, we develop a metric by which to measure disadvantage. Second, we appeal to this metric in order to judge whether an individual 
suffers a disadvantage. On this view, an individual suffers a disadvantage if and only if her opportunities are less valuable than another's, measured in terms of whichever metric we select.

This approach is unsatisfactory for three reasons. First, it may be impossible to identify a metric that can be justified to each member of the community, in the sense that each member accepts the validity of the reasons on which the justification of the metric is based. To see this, let's consider that fact that, whereas some people regard infertility as disadvantageous (say, because they want to bear children), others regard it as advantageous (say, because they want not to worry about the threat of pregnancy). If our metric treats infertility as disadvantaging, then it cannot be justified to the latter. Indeed, it would usurp the latter's judgments regarding the disadvantageousness of infertility. But, if it treats it as advantaging, then it cannot be justified to the former and, similarly, it would usurp the former's judgments regarding the advantageousness of infertility. Whichever is chosen, there is likely to be a section of the community to whom the metric cannot be justified. Let's call this the usurpation objection. (Below, I consider the possibility that our metric could be silent with respect to the (dis)advantageousness of infertility.)

To clarify, the usurpation objection relies upon two premises. The first premise is that, in any just society, individuals will inevitably reach different judgments about values. One reason for this is the existence of the burdens of judgment. These refer to 'the many obstacles to the correct (and conscientious) exercise of our powers of reason and judgment in the ordinary course of political life' (Rawls, 2003: 35). The second premise is that there is something distinctly valuable about the political morality of a community being justifiable to each of its members. This could be because it is important not to usurp each individual's responsibility to determine for herself what it means to live well (Dworkin, 2011). It could be because each individual has a weighty interest in being politically autonomous - that is, in freely identifying with the constraints that she faces, such that she comprehends and endorses the justification of those constraints. ${ }^{8}$ It could be both (Clayton: 2016). Rather than argue for these claims here, I instead simply assume they are correct.

Let's now turn to the second and third objections. Each of these follows from the first objection, but also has independent argumentative force. According to the disrespect 
objection, if any metric inevitably relies upon a justification that an individual may reject, then the metric test risks identifying as (dis)advantaged an individual who rejects the reasons that are offered in support of this judgment. When this is the case, this judgment displays disrespect. It is disrespectful to judge an individual as (dis)advantaged on grounds that she does not accept, because it displays a negative attitude concerning the individual's ability effectively to judge and to advance her own interests in a given situation (Quong, 2011: 100-6).

According to the burdens objection, if any metric inevitably relies upon a justification that an individual may reject, then the metric test also risks identifying as disadvantaged an individual who considers herself to be advantaged in comparison to the individual(s) who must bear the burdens of the corrective action justified in her name, e.g. those who may be required to pay her compensation (Dworkin, 2000: 295). This is a counter-intuitive conclusion that troubles even staunch defenders of the metric test (Cohen, 2011: 33-40).

A defender of the metric test may attempt to respond to the first of these objections, the usurpation objection, by maintaining that it is possible to identify a metric that can be justified to each member of the community. This is the move that John Rawls makes when he advocates the use of an index of social primary goods. The social primary goods refer to all-purpose means, such as income and wealth, that every reasonable individual is presumed to need or want. ${ }^{9}$ This view holds that we should judge whether an individual is disadvantaged by referring solely to her level of access to social primary goods. In this case, perhaps we should treat infertility as neither advantaging nor disadvantaging, given that it is not something that we can presume every reasonable individual needs or wants.

The chief merit of this approach is that it may have the theoretical resources to avoid the usurpation objection. If we determine the content of the metric by referring to what every reasonable individual is presumed to need or want, and not by referring to what makes someone's life go well, then perhaps this does not involve any objectionable form of usurpation. However, this reply fails to rescue the metric test from the disrespect objection or the burdens objection. This is because it is possible that a given individual may be identified as advantaged when judged in terms of social primary goods alone, even though she still considers herself to be comparatively disadvantaged (or vice versa) once everything she cares about is taken into account. Plausibly, this may be the case with an 
individual who scores well in terms of social primary goods but who regards her infertility as severely disadvantaging. To fail to judge her as disadvantaged in this case is clearly objectionable (Arneson, 1992: 217).

By contrast, the envy test avoids each of these three objections. This is most easily seen with respect to the second and third objections. Regarding the disrespect objection, since the envy test identifies disadvantage in a way that is sensitive to each individual's own values, it is incapable of disrespectfully identifying as disadvantaged an individual who rejects the reasons that are offered in support of the judgment that she is disadvantaged. Regarding the burdens objection, since an individual qualifies as disadvantaged only if she regards her opportunities as less valuable than those enjoyed by another, the envy test is incapable of identifying as disadvantaged an individual who considers herself to be advantaged in comparison to the individual(s) who must bear the burdens of the corrective action justified in her name.

With respect to the usurpation objection, things may appear more complicated, since it is not so obvious that the envy test is invulnerable to a similar kind of objection. To see this, let's consider the following variation on Talent:

Disagreement: Whereas Lucky does not envy Unlucky's opportunities, Unlucky envies Lucky's opportunities. However, Lucky rejects the reasons to which Unlucky appeals when justifying her envy: Unlucky envies Lucky's opportunity to earn a high wage but Lucky attaches no value to high wages.

Disagreement prompts us to consider the following question: Isn't Lucky now subject to an account of disadvantage that she rejects? After all, the source of Unlucky's envy is supported by a claim whose validity Lucky rejects, namely a claim about the value of high wages. The alleged force of this objection lies in the fact that it challenges the conclusion that the envy test fares any better than the metric test with respect to the present objection.

In reply, let me note that, though the envy test utilises each individual's own judgment about the value of her opportunities, it does not endorse these judgments (Clayton, 2000: 79; 2016). This is important, since the account of disadvantage that the envy test offers does not depend upon the validity of an individual's judgment. With respect to Disagreement, a defender of the envy test need not take a stand on the value of high 
wages: the force of a complaint does not depend upon that complaint being a good one. Furthermore, we can support this by returning to the burdens of judgment and, in particular, by supposing that individuals have a duty to accept the consequences of the burdens of judgment. For Lucky, this means that, though she may reject the source of Unlucky's envy, she must recognise that, because of the burdens of judgment, Unlucky is entitled to her views about the value of a high wage and, as a result of this, also that Unlucky is entitled to make claims about being disadvantaged on this basis. Thus, what can be justified to Lucky is the envy test itself, not Unlucky's judgment.

The aim of this section has been: first, to cast doubt on the plausibility of the metric test by pressing three related objections against it; and second, to highlight the appeal of the envy test by showing how it is not susceptible to these three objections. My next task is to clarify further the demands of the envy test in order to guard against a fatal misinterpretation.

\section{Envy and the Rotation Objection}

The envy test holds that an individual suffers a disadvantage if and only if her opportunities are less valuable than those enjoyed by another individual, as measured by her own judgments about what makes one's life go well. As I shall make clear in this section, this statement is crucially ambiguous - that is, ambiguous in a way that affects the test's plausibility.

Let's begin by applying the envy test to G. A. Cohen's familiar case of Paul and Fred: Paul has an unchosen expensive taste for photography and Fred has an unchosen inexpensive taste for fishing (1989: 923). One way in which we can reconstruct the envy test is as follows:

(1) Paul is disadvantaged compared to Fred if and only if he thinks himself worse off than Fred.

(2)Paul cannot think himself worse off than Fred unless he would rather be in Fred's shoes.

(3)Paul would not rather be in Fred's shoes. He does not want to love fishing rather than photography.

$\therefore$ (4) Paul is not disadvantaged compared to Fred (Cohen, 2011: 113-14). 
The problem with this argument is that the second premise is false. It is possible for Paul to think himself worse off than Fred, even if Paul would not rather be in Fred's shoes. As Cohen notes, this fact is exposed by the 'shoes' metaphor: 'I can think myself better off in my shoes than I would be in yours while nevertheless thinking myself worse off in mine than you are in yours: yours fit your feet better than mine do' (2011: 114). This is the rotation objection.

In response to the rotation objection, we can distinguish two versions of the envy test. This is where the ambiguity emerges. These two versions correspond to different ways in which we can characterise what it means for an individual to consider herself to be worse off than another. On one reading, it is to do with the choice-worthiness of an individual's opportunities (Scanlon, 1998: 112-13). When this is the case, the envy test states that an individual is disadvantaged if and only if she would prefer to have another individual's opportunities rather than her own. In other words, if there were a pill that switched her opportunities with another's, she would want to take it. On the second reading, the envy test is sensitive to an individual's judgments about the well-being value of her opportunities. When this is the case, the test states that an individual is disadvantaged if and only if she believes that she has less valuable opportunities for well-being than another individual. In order to distinguish these two, let's call the former the choiceworthiness test and the latter the well-being value test. To see how these tests diverge, let's consider the following case:

\footnotetext{
Parent: Mother is a parent of Daughter, who is a very difficult child to parent. Mother invests an uncommonly large amount of time and effort in parenting Daughter and, as a result, Mother believes she has less valuable opportunities for well-being than those enjoyed by parents of less difficult children. However, being her daughter, Mother has a special reason to value the time she spends with Daughter and, with this in mind, she denies that she would want to switch places with a parent of a less difficult child. ${ }^{10}$
}

According to the choice-worthiness test, Mother does not suffer a disadvantage. This is because Mother would not choose to parent another parent's child rather than her own. That is, if there were a pill available to Mother that switched her Daughter with another child, she would not want to take it. By contrast, the well-being value test states that Mother does suffer a disadvantage. This is because, despite not wanting to switch, Mother does regard her opportunities for well-being as less valuable than those enjoyed by parents 
of less difficult children. Accordingly, Parent is a case in which Mother's judgment about the choice-worthiness of her opportunities diverges from her judgment about the wellbeing value of her opportunities.

Parent is important for two reasons. First, it helps to illuminate the distinction between the choice-worthiness test and the well-being value test, which is one that has not yet been appreciated. Commentators regularly elide the two tests, as if they were identical, when in fact they are distinct. For example, in a discussion of Paul the photographer, Dworkin mistakenly elaborates the envy test by appeal to the idea that Paul would feel 'revulsion' were he 'offered a pill that would drain away his interest in art' (Dworkin, 2000: 291). ${ }^{11}$ As explained above, from the fact that Paul would not take such a pill, we can conclude only that he is not disadvantaged according to the choice-worthiness test, but not that he is not disadvantaged according to the well-being value test. The same confusion is also invited by other adherents of the test, including Matthew Clayton (2000: 75; 2016) and Andrew Williams (2002: 379). ${ }^{12}$

Second, the case is also important because it provides intuitive evidence both against the choice-worthiness test and in favour of the well-being value test. It provides evidence against the choice-worthiness test, since the choice-worthiness test generates the intuitively implausible conclusion that Mother is not disadvantaged. This reinforces the rotation objection. The case also provides evidence in favour of the well-being value test. This is because the well-being value test is capable of generating the intuitively plausible conclusion that Mother is disadvantaged. This enables us to avoid the rotation objection.

We can offer further support for the well-being value test, over the choice-worthiness test, by reflecting upon the more general fact that, for the purpose of identifying disadvantage, claims based on judgments about well-being are more relevant than claims based on judgments about choice-worthiness. This conclusion should not be surprising. Claims based on judgments about choice-worthiness are typically polluted by the special reasons that we have to deem as choice-worthy projects to which we are committed or with which we have a joint history (Raz, 2003). In Parent, Mother has a special reason to value spending time with her Daughter, and the existence of this reason should not count against the fact that she suffers disadvantage. 
It is worth pausing to consider what proponents of the choice-worthiness test might say in reply. One possibility is to appeal to the fact that, though Mother would not like to switch children, she may still like to switch the characteristics of the children, and so be the parent of a less difficult child. Perhaps, therefore, there is a meaningful sense in which we can identify Mother as disadvantaged on the basis of the choice-worthiness test. The problem with this move is that we can reach this verdict only with the use of counterfactual comparisons, which involves a comparison of an individual's actual situation with other possible situations in which she might have been. However, in order to be plausible, our analysis of comparative disadvantage must rely upon only interpersonal comparisons, which involves a comparison of an individual's actual situation with others' actual situations (Hurley, 2001: 60). In short, whether we should treat Mother as disadvantaged must depend upon whether her situation is bad relative to other parents, and not upon the theoretical possibility that she could be better off than she in fact is (Williams, 1999: 103).

One reason for this exclusive focus on interpersonal comparisons is that it enables us to avoid the well-known expensive tastes objection, which targets those views that support the subsidization of expensive tastes (Dworkin, 2000: 68-9). To see this, let us consider a case in which Fred, the fisherman, and Paul, the photographer, wash up on island that gives them identical opportunities to fish but no opportunities to photograph. The expensive tastes objection holds that it is implausible to treat Paul as comparatively disadvantaged simply by virtue of the fact that he deems his actual opportunities less valuable than they might have been, if, say, they had washed up on an island with lots of photography equipment. It is on this basis that we should avoid appeals to counterfactual comparisons, and thus reject this revision of the choice-worthiness test.

This is not to say that the choice-worthiness test is not at all relevant to identifying disadvantage. This is because, if an individual qualifies as disadvantaged according to choice-worthiness test, this is sufficient to show that she also qualifies as disadvantaged according to the well-being value test. ${ }^{13}$ If Mother did want to switch opportunities with a parent of a less difficult child, this would entail that she regards her opportunities for wellbeing as less valuable than those enjoyed by a parent of a less difficult child. However, what is significant for our purposes is that the reverse is not true. From the fact that Mother does not want to switch places, we cannot infer that she regards her opportunities 
for well-being as no less valuable than those enjoyed by a parent of a less difficult child. This is why we must focus on the well-being value test rather than the choice-worthiness test.

It may help for me to re-state the conclusions of this section in different terms - ones that better align with the treatment that these issues have received from certain welfare economists. ${ }^{14}$ The central point is that, unlike the choice-worthiness test, the well-being value test allows some preferences to affect the opportunities that we regard an individual as enjoying. That is, in at least some cases, the well-being value test may generate the result an individual is disadvantaged partly as a result of her preferences. Parent helps to illustrate this point. Whereas the choice-worthiness test produces the result that Mother is not disadvantaged, since she would not want to switch places with the mother of a less difficult child, the well-being value test incorporates a concern for Mother's preference to spend time with Daughter, and thus it generates the conclusion that Mother is disadvantaged.

Plainly, this move is consistent with Dworkin's own treatment of the envy test, since he too acknowledges that some preferences can play this role (2000: 82 and 288). For example, he notes that we should regard as disadvantaged an individual who 'cannot stand the taste of ordinary water from the tap' and so 'chooses to buy more expensive bottled water', even though the disadvantage partly results from his preferences (2000: 288). To fail to treat this individual as disadvantaged would be to penalise him for what is effectively a disability. In this respect, Dworkin's envy test differs from those versions of the test most commonly used by welfare economists. This is not to say that all preferences can play this role. The challenge then is to identify which preferences can affect the opportunities that we regard an individual as enjoying. The neglected position that I defend in this section is worth noting in part because it helps to answer this question. More specifically, it states that we should distinguish between different kinds of preferences depending upon how they affect an individual's judgments about her own well-being.

\section{The Mistakes Objection}

In the next two sections, I introduce and respond to the mistakes objection, which has recently been defended by a number of critics of the envy test (Arneson, 2017; Lazenby, 
2016; Slavny, 2017). The objection states that the test is implausible because it allows the judgment that an individual is disadvantaged to be held hostage by mistaken judgments concerning the value of an opportunity. To make full sense of this objection, we must suppose that we can have at least some knowledge of the objective value of various opportunities.

The mistakes objection cuts in two directions. First, there are cases in which, because of a mistaken judgment, the envy test treats an individual as disadvantaged even though, in objective terms, she is not. To see this possibility, let's consider the following case, inspired by one discussed by Anderson (1999: 303):

Jimmy: Jimmy is a very vain person, who mistakenly becomes hysterical over being genetically determined to have a hooked nose. As a result of this, Jimmy envies the opportunities of all those individuals who are not genetically determined to have a hooked nose.

According to the envy test, Jimmy suffers a disadvantage. This is because he envies the opportunities of all those individuals who are not genetically determined to have a hooked nose. Accordingly, Jimmy may be entitled to corrective action, perhaps including compensation, even though he is not disadvantaged when measured in objective terms. Challenging this result's plausibility, Anderson writes: 'It is hard to see how such a preference could create an obligation on the part of society to pay for [Jimmy's] plastic surgery' (1999: 303). If we accept the envy test, Jimmy's mistaken judgment may entitle him to compensation that he may otherwise be denied.

Second, there are cases in which, because of an individual's mistaken judgment, the envy test fails to treat an individual as disadvantaged even though, in objective terms, she is. To see this possibility, let's consider the following case:

\footnotetext{
Masochist: Masochist mistakenly attaches considerable value to suffering severe pain. Masochist experiences severe pain during childbirth but, because of her values, she does not envy the opportunities of those who may give birth without experiencing severe pain. ${ }^{15}$
}

The envy test implies that Masochist is not disadvantaged, even though she is disadvantaged when measured in objective terms. Accordingly, if we accept the envy test, 
Masochist's mistaken judgment may deny her corrective action, such as the offer of pain relief, to which she may otherwise be entitled. This is counter-intuitive (Williams, 2002b: 389). To be sure, I mention these two kinds of cases not because they affect the plausibility of the mistakes objection, but because they demonstrate its versatility and, thus, force.

Having distinguished two directions in which the mistakes objection cuts, let me now distinguish two versions of the mistakes objection. According to the comparative mistakes objection, we ought to reject the envy test on the grounds that it identifies disadvantage in a way that is unfairly sensitive to inequalities between individuals in their ability accurately to judge the value of an opportunity (Arneson, 2017; Lazenby, 2016: 199). A premise of this argument is that some individuals are more likely than others to make these kinds of mistakes. By contrast, according to the non-comparative mistakes objection, we ought to reject the envy test on the grounds that it identifies disadvantage in a way that is sensitive to the mistakes that each individual may make when judging the value of an opportunity (Anderson, 1999; Slavny, 2017). This argument does not rely upon the premise that some individuals are more likely than others to make these kinds of mistakes. ${ }^{16}$

To illuminate further the distinction between the comparative mistakes objection and the non-comparative mistakes objection, let's consider again Masochist. The comparative mistakes objection states that we should reject the envy test if Masochist's mistaken judgment about the value of severe pain is held in part because she is poorer than others at judging the value of her opportunities. According to this objection, we should reject the envy test on the grounds that it effectively penalises Masochist for her comparatively poor native ability accurately to judge the value of her opportunities. The comparative mistakes objection lacks force when there is no inequality between individuals in their ability accurately to judge the value of an opportunity. Perhaps Masochist has identical abilities to others but, because of the burdens of judgment, she has simply come to a different judgment. Even when this is the case, however, the non-comparative mistakes objection still applies. According to this objection, the envy test is implausible because it treats Masochist's mistaken judgment about the value of severe pain as decisive against her being disadvantaged. The force of this objection does not depend upon Masochist being poorer than others at accurately judging the value of an opportunity. 
In the next section, I offer a reply to each of the mistakes objections. Before this, however, I offer two clarifications that weaken, but do not defeat, these objections. The first clarification makes use of the fact that, when an individual clearly makes a mistake about the value of an opportunity, this is often as a result of unjust interference, of the kind that I ruled out in section I. This conclusion grants a defender of the envy test the theoretical resources to respond to many of the cases that appear to lend support to the mistakes objections without having to revise her position. In Jimmy, for example, perhaps we should maintain a sceptical attitude towards Jimmy's envy on the grounds that it is likely that it is the product of judgments held only as a result of the unjust influence of certain social norms. Of course, this fact does not defeat either mistakes objections, since individuals will no doubt continue to make mistaken judgments about the value of an opportunity, even in the absence of unjust interference.

The second clarification is a little lengthier. It concerns how the envy test treats different kinds of mistakes. To begin, let's contrast the following pair of cases, discussed by Hugh Lazenby:

Deafness: Dan is deaf, but incorrectly (let's assume) believes that deafness is no less valuable than being able to hear. Accordingly, Dan incorrectly believes he is no worse off than a hearing person.

Smoking: Sam values his health above all else, but incorrectly believes that smoking is good for one's health. Accordingly, Sam incorrectly believes he is better off than a non-smoker (Lazenby, 2016: 194-5; Williams, 2002a: 37).

The mistakes objections purport to impugn both of these cases. After all, in both cases, it is stipulated that at least one individual makes a mistaken judgment about the value of an opportunity, and this could be due to Dan and Sam being poorer than others at accurately judging the value of an opportunity.

However, a defender of the envy test may plausibly assert that we are permitted to treat these two cases differently for the purpose of identifying disadvantage. This is because we may restrict the scope of the envy test so as to include cases involving mistakes that occur when forming one's values but exclude cases involving mistakes that occur when pursuing one's values. ${ }^{17}$ When this is the case, the envy test is sensitive to the judgments that an individual would form were she not to make a mistake when considering how best to 
pursue her (possibly mistaken) values. Accepting this enables us to resist the implausible conclusion that Sam is not disadvantaged in Smoking. This is because Sam would regard his opportunities as less valuable than a non-smoker's were he not to make a mistake when considering how best to pursue his values. Moreover, this is consistent with my formulation of the envy test in section I, which emphasised the fact that what matters to the envy test is simply that an individual's values imply that her opportunities are less valuable than another's.

In addition to rendering the results of the envy test intuitively more plausible, this move is further supported in two ways. First, there is a general precedent for treating differently cases involving these two kinds of mistakes. To take a familiar example, whereas perhaps I am not morally permitted to prevent you from walking across a dangerous bridge if you mistakenly believe your life is not worth living and are therefore willing to risk death, clearly I am morally permitted to prevent you from walking across a dangerous bridge if you mistakenly believe the bridge is not dangerous (Mill, 1956 [1859]: 117). Thus, whereas my actions ought to be sensitive to mistakes that occur when forming your values, they need not always be sensitive to mistakes that occur when pursuing your values.

Second, there is also a compelling underlying justification for restricting the scope of the envy test in this way. This justification appeals to the fact that, by ignoring an individual's mistakes about how best to pursue her values, we better enable her to pursue the values that she already has (Dworkin, 2000: 492 fn. 7). ${ }^{18}$ An important consequence of this is that we can justify to an individual our account of disadvantage by appealing to reasons that are acceptable to her in the light of the values she holds, even if she does not in fact accept them. $^{19}$

By restricting the scope of the envy test in this way, we weaken the two mistakes objections. This is because a defender of the objections may not criticise the envy test on the basis of cases such as Smoking that involve mistakes about pursuing values. Having said this, this restriction clearly does not defeat either of the mistakes objections. Defenders of the objections may continue to appeal to other cases, such as Deafness, that involve other kinds of mistakes in order to make their point.

\section{Replying to the Mistakes Objections}


A.

My next task is to rebut the two mistakes objections. Let's begin with the comparative mistakes objection. According to this objection, we ought to reject the envy test because it identifies disadvantage in a way that is unfairly sensitive to inequalities between individuals in their ability accurately to make value judgments. We can respond to this objection by noting that an individual's comparatively poor ability accurately to make value judgments might itself be a disadvantage according to the envy test. For instance, if Masochist has less ability than others accurately to judge the value of an opportunity, then presumably she will envy an opportunity enjoyed by others - namely, others' opportunity more accurately to make value judgments. ${ }^{20}$ The envy test thus implies that we should treat this as disadvantaging Masochist. To be sure, when corrective action is justified in this way, it is done so in response to Masochist's comparatively poor ability accurately to make value judgments, not as a response to her mistaken value judgments as such. For this reason, the comparative mistakes objection does not threaten the test's plausibility.

This reply is contingent upon Masochist envying another's opportunities or, more specifically, it is contingent upon Masochist's values implying that she is disadvantaged by virtue of her inferior ability to make value judgments. But, of course, this might not be the case. It may be that Masochist's values do not imply that she is disadvantaged by virtue of her inferior ability. If this were the case, the envy test could not treat her as disadvantaged. Whilst this is correct, it is not clear to me that it is in any way counter-intuitive.

We can further support this verdict by denying that there is any general requirement to treat an individual as disadvantaged simply by virtue of her comparatively poor ability accurately to make value judgments. ${ }^{21}$ To see this, let us suppose for the sake of argument that, in comparison with christians, atheists have comparatively poor ability accurately to make value judgments and that, because of their convictions about religion, atheists are comparative failures in successfully identifying and pursuing goals worthy of pursuit. Let us also suppose that atheists fail to recognise this failure and that their views mistakenly imply that their lives are going at least as well, if not better, than the lives of christians. Under these conditions, it is surely implausible to conclude that the atheists have a claim to be treated as disadvantaged, in the relevant sense. Unlike those who suffer from illness and disease, for example, these atheists are not entitled to corrective action, such that we 
ought to regulate the risk of becoming an atheist or force christians to pay compensation to atheists. For this reason, we should reject the comparative mistakes objection.

B.

The non-comparative mistakes objection is more credible. It has force even in those cases in which an individual does not envy another individual's ability to judge the value of an opportunity. How, then, might we try to meet the non-comparative mistakes objection?

My first response is to deny that the consequences of accepting the envy test are in any way implausible. For instance, in Jimmy, is it really implausible to claim that Jimmy is disadvantaged, when it is stipulated that this is something that causes him to become hysterical? Perhaps not. Similarly, in Deafness, is it really implausible to deny that Dan is disadvantaged, when it is stipulated that Dan believes being deaf is no less valuable than being able to hear? Again, perhaps not. ${ }^{22}$ To be sure, I do not mean to claim that Dan suffers no disadvantage of any kind. For one thing, being deaf may disadvantage Dan by making it more costly for him to participate in democratic decision-making and more difficult for him to relate to others as his political equals. However, it is consistent with the envy test's conclusion that Dan is not disadvantaged, in the specific comparative sense that we have in mind, that he is entitled to other forms of corrective action for other reasons, such as out of a concern for democratic values and political equality.

Though this response softens the blow, it is not a fully satisfactory response to the noncomparative mistakes objection. This is because a defender of the objection can appeal to increasingly extreme cases in order to make her point. For example, let's consider the following variation on Jimmy:

Jennifer Eccles: Jennifer Eccles is a very vain person, who becomes hysterical over having small freckles on her arm, even though they are imperceptible to the naked eye. As a result of this, Jennifer Eccles envies the opportunities of all those individuals who lack any freckles.

In this case, accepting the envy test implies that Jennifer Eccles is disadvantaged. This result is clearly counter-intuitive, and it would be implausible to deny this. ${ }^{23}$ Perhaps the same is true in Masochist. 
One response to this objection is to concede that the envy test has certain limitations, and that in extreme cases we should depart from an individual's own evaluation of the value of her opportunities. ${ }^{24}$ The claim is not that we must abandon the envy test; rather, it is that we should constrain its application. The challenge for proponents of this response is to provide a principled basis for modifying the use of the envy test in this way. At least three possibilities are available. We might resist appeals to the envy test when the beliefs in question are (i) highly uncommon, (ii) epistemically unreasonable, and/or (iii) objectively very costly to those who hold them. Arguably, all three of these are true in the case of Jennifer Eccles.

However, a serious problem remains: whilst the factors help us to distinguish Jennifer Eccles from more familiar cases, it is not obvious that they provide an explanation for constraining the application of the envy test. In short, why ought we not to appeal to the envy test in those cases in which the beliefs in question are highly uncommon, say? Without a principled answer to this question, the present response to the noncomparative mistakes objection seems ad hoc. Moreover, this appears especially problematic given that we know the resulting analysis of these cases may be vulnerable to three objections outlined in section II, namely the usurpation objection, the disrespect objection, and the burdens objection. To be sure, I do not mean to claim that this challenge is an impossible one and, therefore, that this reply must fail. Rather, I am simply highlighting a serious obstacle that needs to be overcome.

For this reason, it helps to consider a second response to the non-comparative mistakes objection, which is to concede that the objection has some force, but to deny that this is sufficient to sanction the rejection of the envy test. That is, we should bite the bullet. Since this response may strike some readers as unconvincing - indeed, anti-climactic - it is necessary to explain why this is not the case. In support of this, I shall make two points. First, let me draw attention again to the costs of abandoning the envy test. The costs that I have in mind are those costs revealed by the three objections to the metric test discussed in section II. Following earlier conclusions, we should note that, if we treat Masochist as disadvantaged, contrary to her own mistaken judgment, then (i) we must appeal to an account of disadvantage that may not be fully consistent with what she believes, (ii) we risk disrespecting Masochist by justifying corrective action on grounds that she does not 
accept, and (iii) we risk identifying her as disadvantaged even though she considers herself to be advantaged in comparison to the individual(s) who must bear the burdens of the corrective action justified in her name, e.g. those who may be required to pay her compensation. Together, I believe these costs count decisively against the force of the non-comparative mistakes objection.

A critic may remain unpersuaded. Though she may acknowledge that the envy test has several virtues, she may maintain that these have insufficient weight to justify accepting the test in the light of the counter-intuitive implications highlighted by the present objection. Let me turn, here, to my second point. It relates to the fact that there is a general trend within liberal political theorising that maintains that we should respect an individual's judgment even if it is mistaken such that it risks seriously jeopardizing her well-being, measured in objective terms. A clear example of this liberal trend is given by the principle of anti-paternalism. If we accept this principle, as many liberals do, we ought to respect an individual's decision to pursue a life of cheap laughs rather than a more valuable life, even though we may know the latter to be much more valuable than the former, when measured in objective terms (Mill, 1956 [1859]; Quong, 2011: ch. 3). In a similar vein, as liberals, we ought to respect an individual's judgment regarding the value of her opportunities, even if we know that her judgment is mistaken such that it risks seriously jeopardizing her well-being, measured in objective terms.

To be sure, my aim is not to defend either the principle of anti-paternalism or the general liberal trend that it reflects. Instead, the aim of this argument is to point out that the implications of the envy test highlighted by the non-comparative mistakes objections are ones that should be familiar to liberals. This is not to deny that they are counter-intuitive implications. Rather, the point is that, if a critic accepts the objection, she may have to give up other familiar principles of liberal political theory, such as the principle of antipaternalism, since they may be equally vulnerable to similar kinds of objections. For many people, including myself, this is too high a price to pay, and it is partly for this reason that we must resist the appeal of the non-comparative mistakes objection.

\section{Conclusion}


The aim of this paper has been to defend the claim that we should treat an individual as disadvantaged if and only if that individual envies another's opportunities. I have sought to achieve this in the first place by explaining this view's superiority over the metric test. I then buttressed my defence of this view by replying to three objections: the rotation objection, the comparative mistakes objection, and the non-comparative mistakes objection. In order to meet these objections, it has been necessary also to reflect upon and engage with broader debates in political theory. I hope that this adds to, rather than subtracts from, the importance of the convictions defended in this paper.

To be sure, in advancing these arguments, I do not claim to have established the all things considered superiority of the envy test over all other ways of identifying disadvantage. I have had to be selective in the objections that I consider and, for this reason, some readers may be unconvinced. None the less, my argument remains important in so far as I articulate and defend a nuanced version of the envy test that, if I am correct, is immune to some of the most pressing objections that have recently been pressed against it. ${ }^{25}$

\section{References}

Anderson, Elizabeth, 'What is the Point of Equality?', Ethics, 109 (1999), 287-337.

Anderson, Elizabeth, 'Rethinking Equality of Opportunity: Comment on Adam Swift's How Not to be a Hypocrite', Theory and Research in Education, 2 (2004), 99-110.

Arneson, Richard, 'Property Rights in Persons', Social Philosophy \& Policy, 9 (1992), 201-30.

Arneson, Richard, 'Dworkin and Luck Egalitarianism: A Comparison' in Serena Olsaretti (ed.), The Oxford Handbook of Distributive Justice (Oxford: Oxford University Press, 2017).

Arnsperger, Christian, 'Envy-Freeness and Distributive Justice', Journal of Economic Surveys, 8 (1994), 155-86.

Clayton, Matthew, 'The Resources of Liberal Equality', Imprints, 5 (2000), 63-84.

Clayton, Matthew, 'Liberal Equality: Political not Erinaceous', Critical Review of International Social and Political Philosophy, 19 (2016), 416-33. 
Cohen, G. A., 'On the Currency of Egalitarian Justice', Ethics, 99 (1989), 906-44.

Cohen, G. A., On the Currency of Egalitarian Justice, and Other Essays in Political Philosophy (Princeton: Princeton University Press, 2011).

Cohen, Joshua, 'Reflections on Rousseau: Autonomy and Democracy', Philosophy \& Public Affairs, 15 (1986), 275-97.

Colburn, Ben, 'Disadvantage, Autonomy, and the Continuity Test', Journal of Applied Philosophy, 31 (2014), 254-70.

Dworkin, Ronald, Sovereign Virtue: The Theory and Practice of Equality (Cambridge, MA.: Harvard University Press, 2000).

Dworkin, Ronald, 'Sovereign Virtue: Revisited', Ethics, 113 (2002), 106-43.

Dworkin, Ronald, Justice for Hedgehogs (Cambridge, MA.: Harvard University Press, 2011).

Feinberg, Joel, The Moral Limits of the Criminal Law, vol. 3 (Oxford: Oxford University Press, 1986).

Freeman, Samuel, Rawls (London: Routledge, 2007).

Hansen, Rasmus Sommer and Midtgaard, Søren Flinch, 'Sinking Cohen’s Flagship - or Why People with Expensive Tastes Should not be Compensated', Journal of Applied Philosophy, 28 (2011), 341-354.

Hurley, Susan, 'Luck and Equality', Proceedings of the Aristotelian Society, Supplementary Volume, 75 (2001), 51-90.

Lazenby, Hugh, 'Mistakes and the Continuity Test', Politics, Philosophy \& Economics, 15 (2016), 190-205.

Mill, J. S., On Liberty (Indianapolis: Bobbs-Merrill, 1956 [1859]).

Nozick, Robert, Anarchy, State and Utopia (New York: Basic Books, 1974).

Parfit, Derek, Reasons and Persons (Oxford: Clarendon Press, 1984).

Quong, Jonathan, Liberalism Without Perfection (Oxford: Oxford University Press, 2011). 
Rawls, John, 'Social Unity and Primary Goods' in Amartya Sen and Bernard Williams (eds.), Utilitarianism and Beyond (Cambridge: Cambridge University Press, 1982), 15986.

Rawls, John, 'The Priority of Right and Ideas of the Good', Philosophy \& Public Affairs, 17 (1988), 251-76.

Rawls, John, Political Liberalism (Columbia: Columbia University Press, 1996).

Rawls, John, A Theory of Justice: Revised Edition (Cambridge, MA.: Harvard University Press, 1999).

Rawls, John, Justice as Fairness: A Restatement (Cambridge, MA.: Harvard University Press, 2003).

Raz, Joseph, The Practice of Value (Oxford: Oxford University Press, 2003).

Robeyns, Ingrid, 'Is Nancy Fraser's critique of theories of distributive justice justified?', Constellations, 10 (2003), 538-53.

Rousseau, Jean-Jacques, The Social Contract and other later political writings (Cambridge: Cambridge University Press, 1997 [1762]).

Scanlon, T. M., What We Owe to Each Other (Cambridge, MA.: Harvard University Press, 1998).

Sen, Amartya, 'The Standard of Living: Lecture I, Concepts and Critiques' in Geoffrey Hawthorn (ed.), The Standard of Living (Cambridge: Cambridge University Press, I987), $1-19$.

Slavny, Adam, 'On Being Wronged and Being Wrong', Politics, Philosophy \& Economics, 16 (2017), 3-24.

Varian, Hal, 'Equity, Envy, and Efficiency', Journal of Economic Theory, 9 (1974), 63-91.

Williams, Andrew 'Resource Egalitarianism and the Limits to Basic Income', Economics and Philosophy, 15 (1999), 85-107.

Williams, Andrew, 'Dworkin on Capability', Ethics, 113 (2002a), 23-39. 
Williams, Andrew, 'Equality for the Ambitious', The Philosophical Quarterly, 52 (2002b), 377-89.

${ }^{1}$ For contrasting approaches, see Cohen (1989: 906-44), Parfit (1984: 493-502), and Rawls (1982: 159-86).

${ }^{2}$ My analysis throughout is indebted to the work of Ronald Dworkin, who defends a specific version of the envy test. See Dworkin (2011: ch. 16). His view diverges in several subtle but crucial respects from those versions of the envy test most commonly used by welfare economists. See section III, Arnsperger (1994: 155-86), and Varian (1974: 63-91).

${ }^{3}$ Many metric tests, including welfarist approaches, also consult an individual's judgments about the value of her opportunities. What is distinctive about the envy test is the way in which it consults an individual's own evaluation of the value of her opportunities, by asking her to compare the value that she sees in her opportunities with the value that she sees in the opportunities that others enjoy. See Clayton (2000: 68).

${ }^{4}$ This is closely associated with the idea of justificatory liberalism. See Clayton (2016) and Hansen and Midtgaard (2011).

${ }^{5}$ For this reason, the position that I defend is consistent with the view stated in Colburn (2014).

${ }^{6}$ See also Anderson (2004: 105).

'Since A may envy B's opportunities at the same time that B envies A's opportunities, it is possible for A to be disadvantaged in comparison with $\mathrm{B}$, whilst $\mathrm{B}$ is disadvantaged in comparison with $\mathrm{A}$. When this is the case, B may be entitled to compensation from $\mathrm{A}$ in virtue of the disadvantage that $\mathrm{B}$ suffers, whilst $\mathrm{A}$ may be entitled to compensation from B in virtue of the disadvantage that A suffers. These transfers may or may not cancel out each other.

${ }^{8}$ See Rawls (1996: 402). This idea has a long historical pedigree, including within the work of Jean-Jacques Rousseau (Rousseau (1997 [1762]), whose "fundamental question” concerns whether it is possible to reconcile the importance of protecting a citizen's freedom with the fact that his relationship to the state is both nonvoluntary and coercive. See also Cohen (1986, pp. 274-88).

${ }^{9}$ For Rawls, the task of identifying social primary goods 'rests on identifying a partial similarity in the structure of citizens' permissible conceptions of the good'. He adds that, even though their content differs, individuals' ambitions 'require for their advancement roughly the same primary goods, that is, the same basic rights, liberties, and opportunities, as well as the same all-purpose means such as income and wealth, all of which are secured by the same social bases of self-respect'. See Rawls (1988: 256-7). See also Freeman (2007: 153-4).

${ }^{10}$ I put aside the fact that Mother may be responsible for having chosen to bring Daughter into the world.

"See also Robeyns (2003: 541).

${ }^{12}$ Without noting the potential differences in these cases, Clayton sometimes discusses cases in which [a individual] believes her life is more successful than those of others', i.e. the well-being value test, but at other times discusses cases in which an individual 'would prefer to have what someone else has in the light of what matters to her', i.e. the choice-worthiness test. See Clayton (2002: 75; 2016). 
${ }^{13}$ I set aside cases in which individuals suffer from status quo aversion, and for whom the grass is always greener. These cases involve a kind of irrationality to which neither the choice-worthiness test nor the wellbeing value test are sensitive.

${ }^{14}$ For an overview, see Arnsperger (1994).

${ }^{15}$ I put aside the possibility that the Masochist's pain may be a component of a more complex pleasure.

${ }^{16}$ There is also a reason to believe that Hugh Lazenby endorses this objection. This is because the noncomparative mistakes objection is essential for upholding Lazenby's more general claim, which is that, when identifying disadvantage, we should be guided solely by balance of evidence, and not by an individual's mistaken judgments. He calls this the correctness test. See Lazenby (2016).

${ }^{17}$ The present distinction is not identical to the distinction between cases involving mistakes about facts and cases involving mistakes about values (or, more precisely, mistakes about facts that are not facts about value), which is mentioned in Lazenby (2016: 194). For example, on the assumption that there is no god, a christian makes a mistake that occurs when forming her values, but it is also a mistake about a fact (i.e. whether or not there is a god). This case shows how the two distinctions may diverge.

${ }^{18}$ See also the discussion of soft paternalism in Feinberg (1986: 12-16).

${ }^{19}$ What is implied by an individual's values may sometimes be unclear. This might be the case in Smoking if the value that Sam attached to his health were roughly equal to the value that he attached to the pleasure of smoking. In this case, it is in the spirit of the envy test to avoid second-guessing whether Sam's values imply that he is disadvantaged, and instead to consult his own actual evaluation of his circumstances. I thank Søren Flinch Midtgaard and Andrew Williams for this suggestion.

${ }^{20}$ As Søren Flinch Midtgaard pointed out to me, this implies that an individual must be able to retain a firstorder value judgment, whilst also being aware of her own comparatively poor ability to make accurate value judgments. I lack the space to defend this premise more fully here.

${ }^{21}$ I thank Andrew Williams for this helpful suggestion.

${ }^{22}$ Commenting on this case, Dworkin adds: 'Why should the community provide Dan with the funds needed for an expensive operation that would restore his hearing, rather than spending those funds in other useful ways, when he not only would not use those funds for that purpose but also would refuse the operation even if it were free?' See Dworkin (2002: 139).

${ }^{23}$ What matters is whether Jennifer Eccles is disadvantaged by having the freckles, and not whether she is disadvantaged by virtue of being afflicted with a psychological condition that causes her to be severely distressed by her physical appearance.

${ }^{24}$ This possibility is suggested by remarks in Williams (2002b).

${ }^{25}$ For helpful written comments or discussions on topics addressed in this paper, I thank audiences at the Newcastle Ethics, Legal and Political Philosophy seminar series and at the Warwick Graduate Conference in Political and Legal Theory 2015, as well as Richard Arneson, David Axelale, Doug Bamford, Chris Bennett, Paul Bou-Habib, Simon Caney, Paula Casal, James Christensen, Matthew Clayton, Dan Halliday, Hugh Lazenby, Andy Mason, Søren Flinch Midtgaard, Dimple Patel, Imogen Peck, Rachel Plummer, Andy Reeve, Adam Slavny, Adam Swift, Victor Tadros, Alex Volacu, Andrew Walton, Andrew Williams, and, most of all, Clare Burgum. 